\title{
COMPARISON OF COLD PRESSOR TEST IN CHILDREN OF HYPERTENSIVE
} AND NON HYPERTENSIVE PARENTS

\author{
Ajay Kumar1, Preeti Rathi², Vinay Agarwal'3, Neelu Saluja4, Seema Choudhary ${ }^{5}$
}

\section{HOW TO CITE THIS ARTICLE:}

Ajay Kumar, Preeti Rathi, Vinay Agarwal, Neelu Saluja, Seema Choudhary. "Comparison of Cold Pressor Test in Children of Hypertensive and Non Hypertensive Parents". Journal of Evolution of Medical and Dental Sciences 2015; Vol. 4, Issue 74, September 14; Page: 12819-12823, DOI: 10.14260/jemds/2015/1848

ABSTRACT: BACKGROUND: Hypertension is a chronic condition of concern due to its role in the causation of coronary heart disease, stroke and vascular complications. Hypertension is a major risk factor for cerebrocardiovascular morbidity and mortality Therefore early identification of risk of hypertension would be important to its prevention. The cold pressor test, in which the response of blood pressure to the stimulus of external cold is measured, has been used to identify hyper reactor individuals who might develop hypertension. So the cold pressure test study examines its effectiveness as a predictor of hypertension. METHODS: Fifty healthy subjects (including males and females) from different MBBS batch in age group of 19-24 yrs were recruited and divided into two groups as study group_ with family history of hypertension ( $\mathrm{FH}+$ ) and control group_ without family history of hypertension (FH-). FH+ group had higher basal and supine systolic and diastolic blood pressor (SBP \& DBP). RESULTS: During cold pressor test (CPT) the FH+ group showed higher rise of SBP and DBP. The hyper reactors (HR) and norm reactors (NR) were categorized by the criteria of a rise of more than $22 \mathrm{mmHg}$ systolic and $18 \mathrm{mmHg}$ diastolic blood pressure during CPT. The study suggests that identification of hyper reactors in population gives a better indication of potential hypertensive's that have positive family history of hypertension.

KEYWORDS: Hypertension, Systolic Blood Pressure, Diastolic Blood Pressure, Cold Pressor Test

INTRODUCTION: Hypertension is a chronic condition of concern due to its role in the causation of coronary heart disease, stroke and vascular complications. It is one of the major risk factor for cardiovascular mortality which accounts $20-50 \%$ of all deaths. Hypertension develops early in life as a result of encounters between stressful environmental factors and genetic predisposition. ${ }^{1}$ Sympathetic over activity plays a significant role in development of neurogenic hypertension. ${ }^{2}$ Hypertension has been reported to be generally associated with sympathetic overactivity. $3,4,5$ The sympathetic response of certain individuals from both normotensive and hypertensive population have been reported to be more pronounced. 6 Again there is dilemma that who among the mild hypertensive eventually developed significant and essential hypertension.7 There are also many other studies which have shown that hypertension is a major risk factor for cerebrocardiovascular morbidity and mortality Therefore early identification of risk of hypertension would be important to its prevention. The cold pressor test, in which the response of blood pressure to the stimulus of external cold is measured, has been used to identify hyper reactor individuals who might develop hypertension. So the cold pressure test study examines its effectiveness as a predictor of hypertension.

MATERIALS \& METHODS: The present study was designed and conducted in the department of Physiology at L.L.R.M Medical College Meerut over a period of 12 months. A total of fifty healthy subjects (Including males \& females) in age group of 19-24 years were recruited from the students of this college doing MBBS course and divided into two groups as study group- with family history of 


\section{ORIGINAL ARTICLE}

hypertension (FH+) (Subjects both males \& females), control group- without family history of hypertension (FH-) (Subjects both males \& females).

The present study was conducted on healthy medical students doing MBBS in the same college. The medical students were considered as study group who's one or both the parents are hypertensive of varying duration and being treated with anti-hypertensive drugs and other medical students of normotensives parents were considered as controls. All subjects included in the study were normotensives.

All the subjects filled up the consent forms giving details regarding family history of hypertension. Ethical committee approval was obtained and procedures done in accordance with the standards. Blood pressure of the subjects was recorded after $10 \mathrm{~min}$ of rest. In cold pressor test, systolic and diastolic blood pressures were recorded in sitting position. The volunteers immersed the left hand upto the elbow in ice cold water (Between 7-10 degree celcius) for $1 \mathrm{~min}$ and not allowed to touch the bottom of the bucket. Blood pressure was noted from the right hand at 30,60 and 90 seconds after immersion. The subject who registered a rise of more than $22 \mathrm{~mm} \mathrm{Hg}$ of systolic blood pressure and $18 \mathrm{~mm}$ of diastolic blood pressure were grouped as hyper reactors. Those subjects whose systolic and diastolic BP did not raise more than 22 and $18 \mathrm{~mm}$ of $\mathrm{Hg}$ were grouped as normoreactors.

RESULTS: Table 1 gives the idea about the distribution of age in children of normotensives and hypertensive. The mean age of control group was 20.96 years and that of study group was 21.00 years. The majority of our subjects in both groups were between 19-20 years of age.

On comparison of difference of means of systolic blood pressure among both the groups, it was observed that the value of systolic blood pressure was higher in study group as compared to controls (Table 2). The observed higher value of mean diastolic pressure in study group with aged matched controls was not statistically significant (Table 3). The maximum rise in systolic and diastolic blood pressure during cold pressor test was significantly higher in children of hypertensives when compared to their age matched controls. The maximum rise of SBP and DBP was higher and statistically significant $(\mathrm{p}<0.0001)$ in study group as compared to their controls in all age groups (Table 4, 5).

DISCUSSION: Hypertension is a disorder of circulation. It is one of the leading cause of morbidity and mortality in the world and will increase into a worldwide important public health problem by $2020^{6}$. It contributes as an important risk factor for coronary artery diseases; stroke and renal diseases and also uncontrolled hypertension ultimately lead to end stage organ failure and death. Our study shows that children of hypertensives had a higher basal SBP and DBP. The higher SBP and DBP in the offspring of hypertensives appear to be due to hereditary influence. It was observed that the value of systolic blood pressure and diastolic blood pressure was higher in study group when compared with controls but it was statistically insignificant in different age groups. Frank A Treiber et al studied the SBP and DBP in 195 boys with mean age of $11.5 \pm 2.2$ year including both with positive and negative family history of hypertension (FH+/FH-). They showed higher systolic BP (105.8mm $\mathrm{Hg})$ with FH+ when compared with subjects having FH- with no significant change in diastolic BP; $\mathrm{FH}+(58.7 \mathrm{~mm}$ Hg), FH-(58.6mm Hg). J Caroline Dekkers et al., ${ }^{8}$ examined the systolic BP in 745 subjects (Age range 4.9-27.5 years) including males and females which constitute equal proportion of Americans Europeans and Africans with positive family history of hypertension and found that subjects with $\mathrm{FH}+$ of essential hypertension had higher systolic BP and stronger increase in systolic BP over time 
than subjects with FH- of essential hypertension. In a study by R. K Rajashekar et al., ${ }^{9}$ in 105 females and 34 male student volunteers, HR showed higher resting seated SBPs and DBPs, and higher rise of SBPs and DBPs during CPT as compared to control groups. In his study the rise of SBPs and DBPs during CPT were also higher in HR as compared to NR of all age groups which is similar to our findings. Similar findings were observed in another study. ${ }^{10}$

Many earlier investigators also reported a greater rise of blood pressure, both systolic and diastolic, during CPT, in patients of essential hypertension as compared to normotensive subjects. ${ }^{11,12}$ Barnett and his associates, ${ }^{13}$ restudied cold pressure test in 207 subjects after 27 yrs. They concluded that children of parents with hypertension are four times more likely to show increased vascular reactivity (Increased blood pressure) than the children of normotensive parents; which underlined the concept of inherited vascular reactivity.

Our study showed that the rise in systolic and diastolic blood pressure during cold pressor test was highly significant among study group with age which was also observed by other coworkers ${ }^{14-16}$ in their work. It was also observed in our study that the recovery phase was slightly delayed in study group than controls but the blood pressure in both the groups came to baseline with in 4 minutes. The higher sympathetic responses with increasing age in study group might be due to hereditary influence on blood pressure and children of hypertensive parents more likely to show increased vascular reactivity. So, it might be more logical to identify the hyper reactors in the population for the early detection of future hypertension.

CONCLUSION: Elevated SBP and DBP in response to cold pressor test and significantly higher number of hyperreactors are observed in the children of hypertensive parents. Thus, the latent period of vascular hyperreactivity can be detected earlier by applying cold pressor test so as to implement early preventive measures to halt the progression of sustained hypertension developing at a future date. It appears that genetic and environmental factors might be responsible for essential hypertension in families.

\section{REFERENCES:}

1. Lopes HF, Bortolotto LA, Szleif C, Kamitsuji CS, Krieger EM, Hemodynamic and metabolic profile in offsprings of malignant hypertensive parents. Hypertension 2001; 38 (2); 616-20.

2. Schneider G.M., Jacobs D.W., Gevirtz R.N., O'Connor D.T., Cardiovascular haemodynamic response to repeated mental stress in normotensive subjects at genetic risk of hypertension: evidence of enhanced reactivity, blunted adaptation and delayed recovery, J Human Hypertens, 17,829-840 (2003)

3. Jacques de Champlain and Marie Reine Van Amerigen. Regulation of Blood Pressure by Sympathetic Nerve fibres and Adrenal Medulla in Normotensive and Hypertensive Rats. Circulation Research 1972; 31: 617-628.

4. Mancia G, Di Rienzo M, Giannattasio C, Parati G, Grassi G. Early and late sympathetic activation in hypertension. Scand Cardiovasc J Suppl 1998; 47: 9-14.

5. DeQuattro V, Feng M. The Sympathetic nervous system: the muse of primary hypertension. J Hum Hypertens 2002 March; 16 Suppl 1: S64-S69.

6. Hines EA, Jr. Significance of Vascular Hyperreaction as measured by Cold-Pressor test. Amer Heart J 1940; 19: 408-416. 


\section{ORIGINAL ARTICLE}

7. Hypertension, Detection and Follow-up Program Group. Five year findings of the hypertension detection and follow-up program I. Reduction in mortality of persons with high blood pressure, including mild hypertension. JAMA 1979; 242: 2562-2571.

8. Dekker's JC, Treiber FA et al. Differential influence of family history of hypertension and premature MI on systolic blood pressure. Pediatrics 2003; 111: 1387

9. R. K. Rajashekar, Yeruva Niveditha. Blood pressure response to cold pressor test in siblings of Hypertensives. Indian J Physiol Pharmacol 2003; 47(4): 453-458.

10. Namrata S. Loya* and A.S. Tambe. Comparative study of cold pressor response in children of hypertensives and normotensives. Al Ameen J Med Sc i 2015; 8(1): 77-80

11. Thacker EA. A comparative study of normal and abnormal blood pressures among university students including the cold pressor test. Amer Heart J 1940; 2: 89.

12. Alam M, Smirk FH. Blood pressure raising reflexes in health, essential hypertension and renal hypertension. Clin Sci 1938; 3: 259.

13. Barnett PH, Hines EA, Jr., Alaxander Schirger and Robert P. Gage: Blood pressure and vascular reactivity to the cold pressor test. JAMA 1963; 183(10): 845-848.

14. Verma V, Singh SK and Ghosh S. Identification of susceptibility to hypertension by the cold pressor test. Indian J Physiol Pharmacol. 2005; 49(1): 119- 20.

15. Pramanik T, Regmi P, Shrestha P. Detection of individuals prone to develop hypertension in their future life. Nepal Med Coll J. 2008; 10(1): 35-7.

16. Garg S, Kumar A and Singh KD. Blood pressure response to cold pressor test in the children of hypertensives. Online J Health Allied Scs. 2010; 9(1): 7.

\begin{tabular}{|c|c|c|c|c|c|c|}
\hline & \multicolumn{3}{|c|}{ Controls } & \multicolumn{3}{c|}{ Study group } \\
\hline Age (yrs) & $\mathbf{n}$ & Mean & SD & $\mathbf{n}$ & Mean & SD \\
\hline $19-20$ & 11 & 19.36 & 0.50 & 11 & 19.45 & 0.68 \\
\hline $21-22$ & 9 & 21.33 & 0.50 & 8 & 21.37 & 0.51 \\
\hline $23-24$ & 5 & 23.80 & 0.44 & 6 & 23.33 & 0.51 \\
\hline Total & $\mathbf{2 5}$ & $\mathbf{2 0 . 9 6}$ & $\mathbf{1 . 7 6}$ & $\mathbf{2 5}$ & $\mathbf{2 1 . 0 0}$ & $\mathbf{1 . 6 8}$ \\
Table 1: Age Distribution in Offspring of Normotensive (Controls) and \\
Hypertensive (Study Group) Parents
\end{tabular}

\begin{tabular}{|c|c|c|c|c|c|c|c|c|}
\hline & \multicolumn{4}{|c|}{ Controls } & \multicolumn{4}{|c|}{ study group } \\
\hline $\begin{array}{l}\text { Age } \\
\text { (yrs) }\end{array}$ & $\mathbf{n}$ & $\begin{array}{l}\text { Mean } \\
\text { systolic } \\
\text { BP }\end{array}$ & SD & $\begin{array}{c}95 \% \\
\text { confidence }\end{array}$ & $\mathbf{N}$ & $\begin{array}{l}\text { Mean } \\
\text { systolic } \\
\text { BP }\end{array}$ & SD & $\begin{array}{c}95 \% \\
\text { confidence }\end{array}$ \\
\hline $19-20$ & 11 & 114.36 & 4.17 & 111.9-116.82 & 11 & 119.63 & 7.78 & $115.03-124.23$ \\
\hline $21-22$ & 9 & 116.66 & 5.00 & 113.39-119.93 & 8 & 119.00 & 4.78 & $115.69-122.31$ \\
\hline $23-24$ & 5 & 121.60 & 2.60 & 119.32-123.88 & 6 & 120.00 & 6.06 & $115.15-124.85$ \\
\hline Total & 25 & 116.64 & 4.92 & $114.71-118.57$ & 25 & 119.52 & 6.30 & $117.05-121.99$ \\
\hline
\end{tabular}

Table 2: Mean \pm Sd Of Systolic Blood Pressure (Mm Of Hg) In Controls And Study Group

\begin{tabular}{|c|c|c|c|c|c|c|c|c|}
\hline & \multicolumn{4}{|c|}{ Controls } & \multicolumn{4}{c|}{ study group } \\
\hline $\begin{array}{c}\text { Age } \\
\text { (yrs) }\end{array}$ & $\mathbf{n}$ & $\begin{array}{c}\text { Mean } \\
\text { Diastolic } \\
\text { BP }\end{array}$ & SD & $\begin{array}{c}\mathbf{9 5 \%} \\
\text { confidence }\end{array}$ & $\mathbf{N}$ & $\begin{array}{c}\text { Mean } \\
\text { Diastolic } \\
\text { BP }\end{array}$ & SD & 95\% confidence \\
\hline $19-20$ & 11 & 77.09 & 5.95 & $73.57-80.61$ & 11 & 79.09 & 5.46 & $75.86-82.32$ \\
\hline $21-22$ & 9 & 79.77 & 4.84 & $76.61-82.93$ & 8 & 82.50 & 2.07 & $81.07-83.93$ \\
\hline
\end{tabular}




\section{ORIGINAL ARTICLE}

\begin{tabular}{|c|c|c|c|c|c|c|c|c|}
\hline $23-24$ & 5 & 80.00 & 2.00 & $78.25-81.75$ & 6 & 81.73 & 5.36 & $75.71-84.29$ \\
\hline Total & $\mathbf{2 5}$ & $\mathbf{7 8 . 6 4}$ & $\mathbf{5 . 0 2}$ & $\mathbf{7 6 . 6 7 - 8 0 . 6 1}$ & $\mathbf{2 5}$ & $\mathbf{8 0 . 4 0}$ & $\mathbf{4 . 6 9}$ & $\mathbf{7 8 . 5 6 - 2 . 2 4}$ \\
\hline
\end{tabular}

Table 3: Mean \pm Sd of Diastolic Blood Pressure (Mm of Hg) In Controls and Study Group

\begin{tabular}{|c|c|c|c|c|c|c|c|c|}
\hline & \multicolumn{9}{|c|}{ Controls } & \multicolumn{3}{c|}{ Study group } \\
\hline $\begin{array}{c}\text { Age } \\
\text { (yrs) }\end{array}$ & $\mathbf{n}$ & $\begin{array}{c}\text { Mean } \\
\text { Diastolic } \\
\text { BP }\end{array}$ & SD & $\begin{array}{c}\mathbf{9 5 \%} \\
\text { confidence }\end{array}$ & $\mathbf{N}$ & $\begin{array}{c}\text { Mean } \\
\text { Diastolic } \\
\text { BP }\end{array}$ & SD & $\begin{array}{c}\mathbf{9 5 \%} \\
\text { confidence }\end{array}$ \\
\hline $19-20$ & 11 & 12.18 & 1.66 & $11.2-13.16$ & 11 & $17.81^{*}$ & 1.40 & $16.98-18.64$ \\
\hline $21-22$ & 9 & 12.66 & 1.41 & $11.74-13.58$ & 8 & $18.75^{*}$ & 1.48 & $17.72-19.78$ \\
\hline $23-24$ & 5 & 11.60 & 1.67 & $10.14-13.06$ & 6 & $18.33^{*}$ & 1.96 & $16.76-19.9$ \\
\hline Total & $\mathbf{2 5}$ & $\mathbf{1 2 . 2 4}$ & $\mathbf{1 . 5 6}$ & $\mathbf{1 1 . 6 3 - 2 . 8 5}$ & $\mathbf{2 5}$ & $\mathbf{1 8 . 2 4}$ & $\mathbf{1 . 5 6}$ & $\mathbf{1 7 . 6 3 - 1 8 . 8 5}$ \\
\hline Table 4: Mean \pm Sd Of Cold Pressor Test (Cpt) Diastolic (Mm Of Hg) In Controls And Study \\
Group
\end{tabular}

$* \mathrm{P}<0.0001$ (statistically significant)

\begin{tabular}{|c|c|c|c|c|c|c|c|c|}
\hline & \multicolumn{3}{|c|}{ Controls } & \multicolumn{3}{|c|}{ Study group } \\
\hline $\begin{array}{c}\text { Age } \\
\text { (yrs) }\end{array}$ & $\mathbf{n}$ & $\begin{array}{c}\text { Mean } \\
\text { Systolic } \\
\text { BP }\end{array}$ & SD & $\mathbf{9 5 \% \text { confidence }}$ & $\mathbf{N}$ & $\begin{array}{c}\text { Mean } \\
\text { Systolic } \\
\text { BP }\end{array}$ & SD & $\begin{array}{c}\mathbf{9 5 \%} \\
\text { confidence }\end{array}$ \\
\hline $19-20$ & 11 & 21.18 & 1.66 & $19.21-24.16$ & 11 & $26.79^{*}$ & 1.61 & $22.98-28.64$ \\
\hline $21-22$ & 9 & 23.66 & 1.41 & $20.74-23.58$ & 8 & $29.83^{*}$ & 1.48 & $25.72-31.78$ \\
\hline $23-24$ & 5 & 19.60 & 1.67 & $17.14-23.06$ & 6 & $26.06^{*}$ & 1.96 & $24.76-28.9$ \\
\hline Total & $\mathbf{2 5}$ & $\mathbf{2 1 . 2 4}$ & $\mathbf{1 . 5 6}$ & $\mathbf{1 9 . 6 3 - 2 4 . 8 5}$ & $\mathbf{2 5}$ & $\mathbf{2 6 . 2 4}$ & $\mathbf{1 . 5 6}$ & $\mathbf{2 4 . 6 3 - 8 . 8 5}$ \\
\hline
\end{tabular}

Table 5: Mean \pm Sd Of Cold Pressor Test (Cpt) Systolic (Mm Of Hg) In Controls And Study Group

${ }^{*} \mathrm{P}<0.0001$ (statistically significant).

\section{AUTHORS:}

1. Ajay Kumar

2. Preeti Rathi

3. Vinay Agarwal

4. Neelu Saluja

5. Seema Choudhary

\section{PARTICULARS OF CONTRIBUTORS:}

1. Assistant Professor, Department of Physiology, MAMC, Agroha, Hisar.

2. Associate Professor, Department of Physiology, LLRM Medical College, Meerut.

3. Professor, Department of Physiology, LLRM Medical College, Meerut.

FINANCIAL OR OTHER

COMPETING INTERESTS: None
4. Associate Professor, Department of Community Medicine, MAMC, Agroha, Hisar.

5. Professor, Department of Community Medicine, MAMC, Agroha, Hisar.

\section{NAME ADDRESS EMAIL ID OF THE} CORRESPONDING AUTHOR:

Ajay Kumar,

Department of Physiology,

Maharaja Agrasen Medical College,

Agroha-125047.

E-mail: acalculia007@gmail.com

Date of Submission: 05/09/2015.

Date of Peer Review: 07/09/2015.

Date of Acceptance: 08/09/2015.

Date of Publishing: 11/09/2015. 